\title{
Medical Toxicology and Public Health-Update on Research and Activities at the Centers for Disease Control and Prevention, and the Agency for Toxic Substances and Disease Registry
}

\author{
Michael Schwartz, M.D., Lieutenant Commandera, U.S. Public Health Service; \\ Susan E. Gorman, PharmD ${ }^{b}$
}

aDivision of Toxicology and Environmental Medicine, ATSDR

bDivision of Strategic National Stockpile, Coordinating Office for Terrorism Preparedness and Emergency Response, CDC

The following is an update on research and activities in which clinical toxicologists are actively involved at CDC/ATSDR. The Journal of Medical Toxicology periodically will highlight some of these activities to illustrate the growing relationship between clinical toxicology and public health.

\section{DIVISION OF TOXICOLOGY AND ENVIRONMENTAL MEDICINE (ATSDR)}

Medical toxicologists serve on the Agency for Toxic Substances and Disease Registry (ATSDR) multi-disciplinary Emergency Response Team, and they have supported public health activities at a number of sites throughout the United States where acute chemical releases occurred. One such event happened in late November 2006. The Emergency Response Team deployed after chemical storage tanks exploded at a facility in Danvers, MA. The explosion released multiple volatile organic chemicals, and a public health evacuation order was given to the community by local public health authorities. Air monitoring data on the chemicals released was collected within hours and analyzed. In conjunction with officials from the Massachusetts Department of Health, U.S. Environmental Protection Agency (EPA) representatives, and local emergency managers, members of the ATSDR response team provided evidence-based guidelines for action levels. (Some examples include determining contaminant levels for when additional offsite monitoring was required, when an evacuation order could be lifted, and others). Also, an air-monitoring plan was developed to assist the EPA with clean-up activities at the site. During the next 4 weeks, air monitoring data was continually analyzed by members of the ATSDR team to ensure that clean-up activities did not result in additional off-site migration of toxic substances at levels above health guidance values.

\section{DIVISION OF STRATEGIC NATIONAL STOCKPILE (COTPER, CDC)}

Under the Centers for Disease Control and Prevention's CHEMPACK Program, nerve agent antidotes are pre-positioned nationwide for emergency use by state and local emergency responders. A CHEMPACK is a cache of federally-owned nerve agent antidotes stored at a location convenient to state and local responders. CHEMPACK caches give emergency responders quick access to life-saving antidotes for treating chemical-associated illnesses. These emergency treatment assets provide participating state and local governments a sustainable resource that improves their capacity to respond quickly to nerve agent events. The CDC's Division of Strategic National Stockpile (DSNS), part of the Coordinating Office for Terrorism Preparedness and Emergency Response, manages the program.

Participating in the CHEMPACK Program is voluntary, and those entities that are part of the program are organized into Project Areas. The CDC allocates CHEMPACK containers to Project Areas based on 2000 U.S. Census data. Project Area officials select the mix of emergency medical services (mostly auto-injectors) and

Note: The findings and conclusions in this article are those of the authors and do not necessarily represent the views of the Centers for Disease Control and Prevention or the Agency for Toxic Substances and Disease Registry. 
hospital (mostly multi-dose vials) containers within their allocation. The selection mix is tailored to meet specific emergency response requirements. Project Area officials provide and maintain storage facilities for the CHEMPACK containers. Locations are selected that will best support emergency response operations. By March 2007, more than 1,500 containers were fielded to 38 Project Areas. Once all CHEMPACK assets are positioned, DSNS will monitor and sustain the fielded containers. This consists of replacing and rotating stock to maintaining the antidotes in a ready-to-use state.

Project Area officials have certain requirements they must meet. After agreeing to participate in the CHEMPACK Program, they must designate a lead agency and a point-of-contact person who will work with DSNS staff members. They also must develop a strategy for using CHEMPACK assets as part of an All-Hazards Emergency Plan. Project Area officials sign memorandums of agreement to store and use CHEMPACK material according to the program guidelines, and they agree to identify the mix of emergency medical services and hospital containers within their official who is a Drug Enforcement Agency registrant. allocation. Finally, accepting custody of CHEMPACK materials requires the signature of an official who is a Drug Enforcement Agency registrant.

The authors have no potential financial conflicts of interest to report. 